\title{
Programmed gRNA Removal System for CRISPR-Cas9-Mediated Multi-Round Genome Editing in Bacillus subtilis
}

\author{
Hayeon Lim ${ }^{1,2}$ and Soo-Keun Choi ${ }^{1,2 *}$ \\ 'Infectious Disease Research Center, Korea Research Institute of Bioscience and Biotechnology, Daejeon, South Korea, \\ 2 Department of Biosystems and Bioengineering, KRIBB School of Biotechnology, Korea University of Science \\ and Technology, Daejeon, South Korea
}

OPEN ACCESS

Edited by:

Vasco Ariston De Carvalho

Azevedo,

Instituto de Ciencias Biologicas,

Universidade Federal de Minas

Gerais, Brazil

Reviewed by:

Zhi-Qiang Xiong,

University of Shanghai for Science and Technology, China

Philippe H. Noirot,

Argonne National Laboratory (DOE),

United States

*Correspondence:

Soo-Keun Choi

sookeun@kribb.re.kr

Specialty section:

This article was submitted to

Evolutionary and Genomic

Microbiology,

a section of the journal

Frontiers in Microbiology

Received: 05 February 2019

Accepted: 06 May 2019

Published: 21 May 2019

Citation:

Lim H and Choi S-K (2019)

Programmed gRNA Removal System

for CRISPR-Cas9-Mediated

Multi-Round Genome Editing

in Bacillus subtilis.

Front. Microbiol. 10:1140.

doi: 10.3389/fmicb.2019.01140
CRISPR/Cas9 has become a simple and powerful genome editing tool for many organisms. However, multi-round genome editing should replace single-guide RNA (sgRNA) every round, which is laborious and time-consuming. Here, we have developed a multi-round genome editing system in which genome editing and the programmed removal of the sgRNA have sequentially occurred in a growth-dependent manner in Bacillus subtilis. The system contains two plasmids, one containing a cas 9 gene and the other containing two sgRNAs and a donor DNA for homology directed repair (HDR). The two sgRNAs are chromosome-targeting (sgRNA $\left.A_{c t}\right)$ and self-targeting (sgRNA $\left.A_{s t}\right)$ under the control of a constitutive promoter and sporulation-specific promoter, respectively. In the growth phase, the sgRNA $\mathrm{ct}$ is transcribed and complexed with the Cas9 to edit the chromosomal target, while the sgRNA $A_{s t}$ is transcribed in the sporulation phase and complexed with the Cas 9 to attack its own plasmid. Therefore, the system automatically makes the cell ready for next-round genome editing during cultivation. The system was approved through the sequential deletion of eight extracellular protease genes in the $B$. subtilis, suggesting that it can be used for versatile applications in multi-round genome editing.

Keywords: Bacillus subtilis, CRISPR/Cas9, self-curing, genome editing, extracellular protease

\section{INTRODUCTION}

A type II clustered regularly interspaced short palindromic repeat (CRISPR)/Cas9 system of Streptococcus pyogenes, derived from the bacterial adaptive immune system has been developed into convenient genome engineering tools for diverse organisms, such as Escherichia coli (Jiang et al., 2015), Streptomyces spp. (Cobb et al., 2014), Saccharomyces cerevisiae (DiCarlo et al., 2013), mice (Shen et al., 2013), Bomyx mori (Wang et al., 2013), Drosophila (Bassett et al., 2013), crop plants (Shan et al., 2013), and human cell lines (Mali et al., 2013). The CRISPR/Cas9 system requires the CRISPR-associated protein (Cas9), a trans-activating CRISPR RNA (tracrRNA), and a CRISPR RNA (crRNA). A synthetic single guide RNA (sgRNA) is constructed by fusing together the tracrRNA and the crRNA. The endonuclease Cas9 and sgRNA, including a $20 \mathrm{bp}$ 
target sequence, which is decided by protospacer adjacent motif (PAM), are enough to make a double-strand DNA break (DSB) in a specific region of the genome (Jinek et al., 2012; Barrangou and Marraffini, 2014). The DSB can be repaired using two mechanisms - the homology directed repair (HDR) and the nonhomologous end joining (NHEJ). For the HDR pathway, donor DNA fragment that is homologous to the region flanking DSB site is required to repair the cleavage site. The NHEJ system repairs the broken end without the donor DNA and results in the insertion or deletion (indel) mutations. The CRISPR/Cas9 systems can provide an efficient tool for editing the genome (Doudna and Charpentier, 2014).

Several types of CRISPR/Cas9-based genome editing system have been reported in $B$. subtilis, including chromosomeintegrated method, single-, or two-plasmid systems (Hong et al., 2018). The chromosome-integrated CRISPR/Cas9 was used for single or double gene mutation, and for the insertion of a $2.9 \mathrm{~kb}$ hyaluronic acid biosynthetic operon. However, this method has a limitation - the gRNA integration site must be restored to its original form in order to introduce a new gRNA cassette (Westbrook et al., 2016). A singleplasmid-based method was used for the disruption of multiple genes, which are srfC, spoIIAC, nprE, aprE, and amyE, with an efficiency of 33-53\% (Zhang et al., 2016). In addition, a two-plasmid CRISPR/Cas9 system was introduced for spo0A deletion, sigE point mutation, $g f p$ gene insertion, and largesized gene deletion in B. subtilis (So et al., 2017). The two-plasmid system showed the highest mutation efficiency. However, the plasmid-based gene editing systems still require an iterative process of removing the plasmid containing the previous sgRNA, and for introducing the plasmid carrying a new sgRNA for the multi-round genome editing. The previous methods for plasmid removal were usually dependent on a temperature sensitive replication origin or a traditional negative selection method, which are labor-intensive and time-consuming (Trevors, 1986). Therefore, a method that can remove the specific plasmid DNA with high efficiency would facilitate multiround genome editing.

In E. coli, CRISPR/Cas9-mediated plasmid curing methods have used replicon, or antibiotic resistant marker-targeting sgRNAs for plasmid recycling (Jiang et al., 2015; Li et al., 2015; Ronda et al., 2016; Lauritsen et al., 2017). These systems have used inducible promoters for the controlled transcription of the sgRNAs in order to avoid the transcription of the self-targeting sgRNA (sgRNA $\left.{ }_{s t}\right)$, prior to chromosome-targeting sgRNA $\left(\operatorname{sgRNA}_{\mathrm{ct}}\right)$. However, the CRISPR/Cas9-mediated plasmid curing has not yet been reported in B. subtilis. Several inducible promoters have been used in the B. subtilis, such as $\mathrm{P}_{\text {spac }}$ and $\mathrm{P}_{\mathrm{xyl}}$. However, they have substantial basal expression levels despite the absence of an inducer (Bhavsar et al., 2001). Using a sporulationspecific promoter for tightly controlled transcription of the sgRNA $_{\text {st }}$, we have developed here a CRISPR/Cas9-based multiround genome editing system in which the genome editing and automatic plasmid curing occur in sequence during cultivation. The system was used to construct a $B$. subtilis mutant, containing eight extracellular proteases' deletion without the remainder of any foreign DNA trace.

\section{MATERIALS AND METHODS}

\section{Strains and Culture Conditions}

The plasmids and B. subtilis strains used in this study are listed in Table 1. E. coli MC1061 was used to construct the recombinant plasmids. B. subtilis cells were cultured in Luria-Bertani (LB), LB agar (Difco Laboratories, Detroit, MI, United States) and $2 \times$ GYS (2 g/L glucose, $4 \mathrm{~g} / \mathrm{L}\left(\mathrm{NH}_{4}\right)_{2} \mathrm{SO}_{4}, 4 \mathrm{~g} / \mathrm{L}$ yeast extract, $1 \mathrm{~g} / \mathrm{L} \mathrm{K}_{2} \mathrm{HPO}_{4}, 0.82 \mathrm{~g} / \mathrm{L} \mathrm{MgSO} 4 \cdot 7 \mathrm{H}_{2} \mathrm{O}, 0.16 \mathrm{~g} / \mathrm{L}$ $\mathrm{CaCl}_{2} \cdot 2 \mathrm{H}_{2} \mathrm{O}$, and $0.14 \mathrm{~g} / \mathrm{L} \mathrm{MnSO}_{4} \cdot 5 \mathrm{H}_{2} \mathrm{O}, \mathrm{pH} 7.0$ ) for sporulation at $37^{\circ} \mathrm{C}$. To test the efficiency of the plasmid cleavage, $100 \mathrm{mM}$ IPTG (Isopropyl $\beta$-D-1-thiogalactopyranoside) was added to the $2 \times$ GYS (final concentration of $1 \mathrm{mM}$ ), named $2 \times$ GYS-I. When required, the antibiotics were supplemented with ampicillin $(100 \mu \mathrm{g} / \mathrm{ml})$, neomycin $(10 \mu \mathrm{g} / \mathrm{ml})$ or chloramphenicol $(5 \mu \mathrm{g}$ $/ \mathrm{ml}$ ). Transformation of $B$. subtilis was carried out utilizing the two-step transformation procedure (Harwood and Cutting, 1990) except that the EGTA (ethylene glycol-bis(2-aminoethyl ether) N, $\mathrm{N}, \mathrm{N}^{\prime}, \mathrm{N}^{\prime}$-tetraacetic acid) was not used.

\section{Plasmids Construction}

The primers used in this study are listed in Table 2. The sporulation-specific promoter $\left(\mathrm{P}_{\text {spoIVA }}\right)$ and sgRNA $\mathrm{R}_{\text {st }}$, containing $20 \mathrm{bp}$ of self-targeting sequences, was obtained through a fusion polymerase chain reaction (PCR) with primers spoIVA-rep-F1 and spoIVA-rep-R1. The PCR product was digested with EcoRI and BamHI and inserted into corresponding sites of plasmid pAD123 (Jeong D.E. et al., 2018) to construct the pSC1. To introduce the synthetic sgRNA module under the control of the constitute promoter $\left(\mathrm{P}_{\text {ara }}\right)$ into the plasmid pSC1, primers g-AarI-F1 and g-AarI-R1 were used to amplify the promoter and the synthetic sgRNA module, using the pAgR (So et al., 2017) as a template. The PCR product was digested with BglII and NsiI and ligated with large a fragment of BamHI- and NsiI-digested pSC1, to construct plasmid pG2.

The 20 bp gRNA-containing oligonucleotides were generated by mixing synthetic primers $\mathrm{x}-\mathrm{gF} 1$ and $\mathrm{x}-\mathrm{gR} 1(x$ indicates the target genes; aprE, nprE, epr, bpr, mpr, nprB, vpr, and wprA). The oligonucleotides were ligated with AarI-digested pG2 to produce eight pG2 derivatives. For further cloning of donor DNAs, $500 \mathrm{bp}$ fragments of each of the $\mathrm{N}$ - and C-terminus of the target site were amplified using the $B$. subtilis 168 chromosome as a template, with primer sets $\mathrm{x}-\mathrm{NF} 1 / \mathrm{x}-\mathrm{NR} 1$ and $\mathrm{x}-\mathrm{CF} 1 / \mathrm{x}-$ CR1. The fusion PCR of the two DNA fragments, with primers $\mathrm{x}-\mathrm{NF} 1 / \mathrm{x}-\mathrm{CR} 1$, resulted in a $1 \mathrm{~kb}$ donor DNA. Then the donor DNAs were digested with BamHI and SpeI and ligated with the corresponding the pG2 derivatives to convert pG2-aE to pG2wA (NheI instead of BamHI in pG2-nB) (Table 1). To construct pG-aE, EcoRI- and HindIII-, digested pG2-aE was treated with dNTPs and the Klenow fragment, followed by blunt end ligation.

\section{Serial Gene Editing in B. subtilis}

BS-C100, a B. subtilis 168 derivative carrying pHCas9 (So et al., 2017) was transformed with the sgRNAs-containing plasmids. The transformed cells were spread on LB agar plate supplemented with chloramphenicol $(5 \mu \mathrm{g} / \mathrm{ml})$ and neomycin $(10 \mu \mathrm{g} / \mathrm{ml})$. One 
TABLE 1 | Bacillus strains and plasmids used in this study.

\begin{tabular}{|c|c|c|}
\hline $\begin{array}{l}\text { Strain/ } \\
\text { plasmid }\end{array}$ & $\begin{array}{l}\text { Genotype/ } \\
\text { description }\end{array}$ & References \\
\hline \multicolumn{3}{|c|}{ BACILLUS STRAINS } \\
\hline $\begin{array}{l}\text { B. subtilis } \\
168\end{array}$ & Tryptophan auxotrophic (trpC2) & $\begin{array}{l}\text { Laboratory } \\
\text { stock }\end{array}$ \\
\hline BS-C100 & $\begin{array}{l}\text { B. subtilis } 168 \text { containing } \\
\text { plasmid pHCas } 9\end{array}$ & So et al., 2017 \\
\hline BS-D119a & $\begin{array}{l}\text { BS-C100 containing plasmid } \\
\text { pSC1 }\end{array}$ & This study \\
\hline BS-D119b & $\begin{array}{l}\text { BS-C100 } \triangle a p r E \text { containing } \\
\text { plasmid pG2-aE }\end{array}$ & This study \\
\hline BS-D119c & $\begin{array}{l}\text { BS-C100 } \triangle \text { aprE containing } \\
\text { plasmid pG-aE }\end{array}$ & This study \\
\hline BS-D119 & BS-C100 $\triangle$ aprE & This study \\
\hline BS-D120 & BS-C100 $\triangle a p r E ~ \triangle n p r E$ & This study \\
\hline BS-D121 & BS-C100 $\triangle a p r E ~ \Delta n p r E \Delta e p r$ & This study \\
\hline BS-D122 & $\begin{array}{l}\text { BS-C100 } \triangle a p r E \triangle n p r E \Delta e p r \\
\Delta b p r\end{array}$ & This study \\
\hline BS-D123 & $\begin{array}{l}\text { BS-C100 } \triangle a p r E \triangle n p r E \triangle e p r \\
\Delta b p r \Delta m p r\end{array}$ & This study \\
\hline BS-D124 & $\begin{array}{l}\text { BS-C100 } \triangle \text { aprE } \triangle n p r E \Delta e p r \\
\Delta b p r \Delta m p r \Delta n p r B\end{array}$ & This study \\
\hline BS-D125 & $\begin{array}{l}\text { BS-C100 } \triangle a p r E \triangle n p r E \\
\Delta \text { epr } \Delta b p r \Delta m p r \Delta n p r B \Delta v p r\end{array}$ & This study \\
\hline BS-D126 & $\begin{array}{l}\text { BS-C100 } \triangle \text { aprE } \triangle n p r E \Delta e p r \\
\triangle b p r \Delta m p r \triangle n p r B \Delta v p r \\
\Delta w p r A\end{array}$ & This study \\
\hline \multicolumn{3}{|c|}{ PLASMIDS } \\
\hline pAD123 & E. coli-Bacillus shuttle vector & $\begin{array}{l}\text { Bacillus } \\
\text { Genetic Stock } \\
\text { Center }\end{array}$ \\
\hline $\mathrm{pAgR}$ & $\begin{array}{l}\text { Plasmid pAD123 derivative } \\
\text { containing synthetic sgRNA } \\
\text { module }\end{array}$ & So et al., 2017 \\
\hline pSC1 & $\begin{array}{l}\text { Plasmid pAD123 derivative } \\
\text { containing sgRNA module with } \\
20 \text { bp self-targeting gRNA } \\
\text { under the control of } \\
\text { sporulation-specific promoter } \\
\text { P }_{\text {spolvA }}\end{array}$ & This study \\
\hline pG2 & $\begin{array}{l}\text { Plasmid pSC1 containing } \\
\text { synthetic sgRNA module under } \\
\text { the control of the constitute } \\
\text { promoter (Para) }\end{array}$ & This study \\
\hline $\mathrm{pG} 2-\mathrm{aE}$ & $\begin{array}{l}\text { Plasmid pG2 containing } \\
\text { aprE-targeting } 20 \text { bp gRNA } \\
\text { and } 1 \mathrm{~kb} \text { Donor DNA }\end{array}$ & This study \\
\hline pG-aE & $\begin{array}{l}\text { Plasmid pG2-aE without } \\
\text { sporulation-specific promoter } \\
\text { P }_{\text {spolvA and } 20 \text { bp self-targeting }} \\
\text { gRNA }\end{array}$ & This study \\
\hline pG2-nE & $\begin{array}{l}\text { Plasmid pG2 containing } \\
\text { nprE-targeting } 20 \text { bp gRNA } \\
\text { and } 1 \mathrm{~kb} \text { Donor DNA }\end{array}$ & This study \\
\hline pG2-er & $\begin{array}{l}\text { Plasmid pG2 containing } \\
\text { epr-targeting } 20 \text { bp gRNA and } \\
1 \text { kb Donor DNA }\end{array}$ & This study \\
\hline pG2-br & $\begin{array}{l}\text { Plasmid pG2 containing } \\
\text { bpr-targeting } 20 \text { bp gRNA and } \\
1 \text { kb Donor DNA }\end{array}$ & This study \\
\hline
\end{tabular}

(Continued)
TABLE 1 | Continued

\begin{tabular}{lll}
\hline $\begin{array}{l}\text { Strain/ } \\
\text { plasmid }\end{array}$ & $\begin{array}{l}\text { Genotype/ } \\
\text { description }\end{array}$ & References \\
\hline pG2-mr & $\begin{array}{l}\text { Plasmid pG2 containing } \\
\text { mpr-targeting 20 bp gRNA and } \\
1 \text { kb Donor DNA }\end{array}$ & This study \\
& $\begin{array}{l}\text { Plasmid pG2 containing } \\
\text { nprB-targeting 20 bp gRNA } \\
\text { pG2-nB }\end{array}$ & This study \\
& $\begin{array}{l}\text { Plasmid pG2 containing } \\
\text { vpr-targeting 20 bp gRNA and } \\
\text { 1 kb Donor DNA }\end{array}$ & \\
& Plasmid pG2 containing & This study \\
pG2-wA & wprA-targeting 20 bp gRNA & This study \\
& and 1 kb Donor DNA & \\
\hline
\end{tabular}

colony selected from the plate was cultured in the $2 \times$ GYS $-\mathrm{I}$ medium containing neomycin $(10 \mu \mathrm{g} / \mathrm{ml})$ for $16 \mathrm{~h}$. Subsequently, the cells were heat-treated at $80^{\circ} \mathrm{C}$ for $1 \mathrm{~h}$ and spread on the $\mathrm{LB}$ agar plate containing neomycin $(10 \mu \mathrm{g} / \mathrm{ml})$. The colonies on the plate were observed for antibiotic sensitivity to chloramphenicol $(5 \mu \mathrm{g} / \mathrm{ml})$ to select the colonies that have been removed from the sgRNAs-containing plasmid. The mutations were confirmed by the colony of PCR, DNA sequencing, and protease assay.

\section{Protease Assay}

Protease assay was performed using FTC (fluorescein isothiocyante)-casein as a substrate provided by the Pierce Fluorescent Protease Assay Kit (Thermo Scientific, Rockford, IL, United States). Bacillus cells were cultured in LB medium for $16 \mathrm{~h}$ at $37^{\circ} \mathrm{C}$. Following this, the culture supernatants were collected by centrifugation at $10,000 \times g$ for $5 \mathrm{~min}$. The FTC-casein working reagent $(100 \mu \mathrm{l})$ was mixed with $100 \mu \mathrm{l}$ of the diluted supernatants $\left(2^{-8}\right)$ and incubated at room temperature for $24 \mathrm{~h}$. The $10 \%$ trichloroacetic acid $(400 \mu \mathrm{l})$ was added to the mixture and incubated at ambient temperature for $5 \mathrm{~min}$. After centrifugation at $10,000 \times g$ for $5 \mathrm{~min}, 300 \mu \mathrm{l}$ of the supernatant was mixed with $900 \mu \mathrm{l}$ of $0.5 \mathrm{M}$ Tris, $\mathrm{pH}$ 9, to measure fluorescence. Fluorescence intensity (excitation, $485 \mathrm{~nm}$; emission, $535 \mathrm{~nm}$ ) was measured using the $\operatorname{TriStar}^{2} \mathrm{LB}$ 942 Multimode Reader (Berthold Technologies GmbH \& Co. KG, Bad Wildbad, Germany). Blank fluorescence was subtracted from each measurement and the fluorescence reading was normalized to $\mathrm{OD}_{600}=1$.

\section{RESULTS}

\section{Construction of the Self-Targeting sgRNA Module}

Most of the CRISPR/Cas9-based genome editing in B. subtilis has been performed through plasmid-mediated methods (Altenbuchner, 2016; Zhang et al., 2016; Burby and Simmons, 2017; So et al., 2017). In multi-round genome editing, the elimination of sgRNA-containing plasmid is essential for the following round. It was reported that the CRISPR/Cas9 system 
TABLE 2 | Oligonucleotides and Primers used in this study.

\begin{tabular}{|c|c|}
\hline $\begin{array}{l}\text { Oligonuc } \\
\text { leotide }\end{array}$ & Sequence $\left(5^{\prime} \rightarrow 3^{\prime}\right)$ \\
\hline aprE-gF1 & Attgaccgattgagttattaagag \\
\hline aprE-gR1 & Aaacctcttaataactcaatcggt \\
\hline nprE-gF1 & Attgagacaagcgtgcccggaagg \\
\hline nprE-gR1 & Aaacccttccgggcacgcttgtct \\
\hline epr-gF1 & Attgttaaaccagtattatgcaac \\
\hline epr-gR1 & Aaacgttgcataatactggtttaa \\
\hline bpr-gF1 & Attgataacggaaagacatcaagc \\
\hline bpr-gR1 & Aaacgcttgatgtctttccgttat \\
\hline mpr-gF1 & Attgtatccgtacggtacttattc \\
\hline mpr-gR1 & Aaacgaataagtaccgtacggata \\
\hline nprB-gF1 & Attgtctcaactgatcgggtatac \\
\hline nprB-gR1 & Aaacgtatacccgatcagttgaga \\
\hline vpr-gF1 & Attgaaagtcgccgttgtcaaacg \\
\hline vpr-gR1 & Aaaccgtttgacaacggcgacttt \\
\hline wprA-gF1 & Attgatattcagtacccttatcaa \\
\hline wprA-gR1 & Aaacttgataagggtactgaatat \\
\hline Primer & Sequence $\left(5^{\prime} \rightarrow 3^{\prime}\right)$ \\
\hline $\begin{array}{l}\text { spolvA- } \\
\text { rep-F1 }\end{array}$ & $\begin{array}{l}\text { Caagaattcgatgtcatattcaaataggacaacgtcatacacatatagtgca } \\
\text { aatttctgcgatgatggagttttagagctagaaatagcaagttaaa }\end{array}$ \\
\hline $\begin{array}{l}\text { spolvA- } \\
\text { rep-R1 }\end{array}$ & $\begin{array}{l}\text { Agaggatccaaaaaaagcaccgactcggtgccactttttcaagttgataac } \\
\text { ggactagccttattttaacttgctatttctagctctaaaactccat }\end{array}$ \\
\hline g-Aarl-F1 & Taagatctaagcttaaagattgacagtataatagtc \\
\hline g-Aarl-R1 & Aaaatgcatactagtagctagcaggatccaaaaaaagcaccgactc \\
\hline aprE-NF1 & Tggatcctagttatttcgagtctctacgg \\
\hline aprE-NR1 & tgtgcaatatgatcttcttcc \\
\hline aprE-CF1 & Ggaagaagatcatattgcacatcggctaccctgcaaaatat \\
\hline aprE-CR1 & Atactagtcggtgcttgtgaagattttca \\
\hline nprE-NF1 & Tggatccttatcaatcagcctgccaggt \\
\hline nprE-NR1 & Taagcaagacgatagctgcc \\
\hline nprE-CF1 & Ggcagctatcgtcttgcttatgatggcgacggttcattctt \\
\hline nprE-CR1 & Atactagtcttcaactttagcggcatca \\
\hline epr-NF1 & Gcagaccaggagacagtaaaa \\
\hline epr-NR1 & Tcgtgccaaggctcatattga \\
\hline epr-CF1 & Tcaatatgagccttggcacgatgccgaactccgacgccaaaa \\
\hline epr-CR1 & Atactagttcttcactttgtctaaccgtt \\
\hline bpr-NF1 & Tggatccatttcctgattcaccgaataa \\
\hline bpr-NR1 & Cggaactccccattcccagtt \\
\hline bpr-CF1 & Aactgggaatggggagttccgatcagaacaaggctatacag \\
\hline bpr-CR1 & Atactagtataaccgacgaaaggcttcaa \\
\hline mpr-NF1 & Tggatcctgctgctgattcagttgaaa \\
\hline mpr-NR1 & Ggctgtaaggtttgaatgttt \\
\hline mpr-CF1 & Aaacattcaaaccttacagccctgaaacgtataagctgacct \\
\hline mpr-CR1 & Atactagtgagatgtgatgggttactgat \\
\hline nprB-NF1 & Tgctagcatcaaaccccttcatacatca \\
\hline nprB-NR1 & Cagatgtcgagagtctcacaa \\
\hline nprB-CF1 & Ttgtgagactctcgacatctgatgaaatcacacacgcagtca \\
\hline nprB-CR1 & Atactagtatagaatgccgacagcctca \\
\hline vpr-NF1 & Tggatcctctccgcaaatggatgacagt \\
\hline vpr-NR1 & Ctgttgccgtttgaggtaac \\
\hline vpr-CF1 & Gttacctcaaacggcaacagtgttatggatacgtggatgat \\
\hline vpr-CR1 & Atactagttacttttgcagtggctttccc \\
\hline wprA-NF1 & Tggatccggttgaaatgagtgtcgatca \\
\hline
\end{tabular}

(Continued)
TABLE 2 | Continued

\begin{tabular}{ll}
\hline $\begin{array}{l}\text { Oligonuc } \\
\text { leotide }\end{array}$ & Sequence $\left(\mathbf{5}^{\prime} \rightarrow \mathbf{3}^{\prime}\right)$ \\
\hline wprA-NR1 & Ttatgtacggatgagaggct \\
wprA-CF1 & Agcctctcatccgtacataattgcagcccaaagcgataac \\
wprA-CR1 & Atactagtagcttaggatttgagcaaac \\
\hline
\end{tabular}

Underlined sequences are the restriction enzyme sites.

Bolded sequences represent the 20 bp synthetic gRNA.

using $\operatorname{sgRNA}_{\text {st }}$ was used as a tool for plasmid removal in E. coli (Jiang et al., 2015). However, the transcription of the sgRNA $\mathrm{st}_{\mathrm{s}}$ needs to be tightly regulated because the unnecessary removal of $\mathrm{sgRNA}_{\mathrm{st}}$-containing plasmid through leaky transcriptions may result in the simultaneous removal of $\operatorname{sgRNA} A_{c t}$, which can hinder the genome editing.

In $B$. subtilis, the expression of sporulation-relating genes are tightly regulated by the phosphorylation of the master regulator Spo0A, and by the cascade activation of sporulationspecific sigma factors, $\sigma^{F}, \sigma^{E}, \sigma^{G}$, and $\sigma^{K}$ (Piggot and Hilbert, 2004). Thus, a sporulation-specific promoter $\left(\mathrm{P}_{\text {spoIVA }}\right)$ (Roels et al., 1992; Hilbert and Piggot, 2004) was selected for the tight-control transcription of the sgRNA $A_{\text {st }}$. The sgRNA ${ }_{\text {st }}$ contains $20 \mathrm{bp}$ gRNA sequence targeting replication origin of plasmid pAD123 (Figure 1A). To confirm the self-curing system, the B. subtilis strain BS-C100 containing pHCas9 (So et al., 2017) was transformed with the plasmid pSC1 containing $\operatorname{sgRNA}_{\mathrm{st}}$. The resulting strains of $\mathrm{BS}-\mathrm{D} 119 \mathrm{a}$ were cultured for $16 \mathrm{~h}$ in a sporulation medium $(2 \times \mathrm{GYS})$ containing neomycin. Following the heat treatment, the cells were spread on the LB neomycin or chloramphenicol agar plate. We expected that the $\operatorname{sgRNA}_{\text {st }} / \mathrm{Cas} 9$ complex would attack its own replication origin during the sporulation phase to exhibit chloramphenicol sensitivity (Figure 1B). All seventy colonies selected for antibiotic susceptibility tests showed sensitivity to chloramphenicol, indicating that the curing system works well with 100\% efficiency (Figure 1C).

\section{Growth-Phase Dependent Automatic sgRNAs-Exclusion System}

Using the curing system, we developed an efficient, multiround genome editing process for B. subtilis (Figure 2). The system contains two plasmids: One carries a cas 9 gene, and the other contains a donor DNA and two sgRNAs - sgRNA and $\mathrm{sgRNA}_{\mathrm{ct}}$. In the growth phase, Cas9 and $\mathrm{sgRNA}_{\mathrm{ct}}$ are synthesized by the constitutive promoter and complexed to cleave the chromosomal target. The target editing occurs through a homologous recombination between the target and the donor DNA. In the sporulation phase, the $\operatorname{sgRNA}_{\text {st }}$ is synthesized and complexed with the Cas9 to cleave the sgRNAs-bearing plasmid. The resulting sgRNA-free cells are ready for the next round of editing.

To confirm the system, two plasmids - pG-aE and pG2$\mathrm{aE}$ - were constructed (Figure 3A). The $\mathrm{pG}-\mathrm{aE}$ contains aprEtargeting sgRNA, under the control of constitutive a $\mathrm{P}_{\text {ara }}$ 


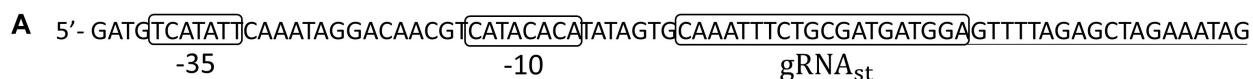

CAAGTTAAAATAAGGCTAGTCCGTTATCAACTTGAAAAAGTGGCACCGAGTCGGTGCTTTTTTT -3'

Cas9 binding scaffold

Transcriptional terminator

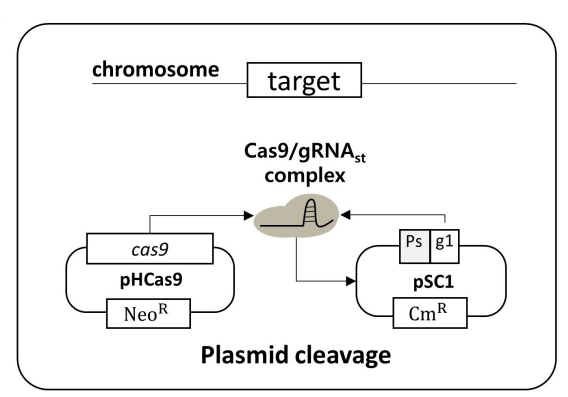

C

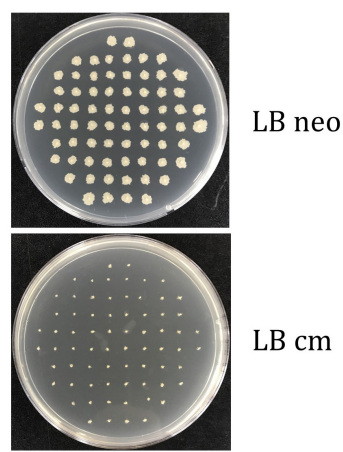

FIGURE 1 | Development of plasmid curing system using Cas9 and self-targeting sgRNA (sgRNAst). (A) Sequence of a self-targeting sgRNA under the control of $\mathrm{P}_{\text {spolva }}$ promoter, 20 bp self-targeting gRNA (gRNA $\mathrm{st}_{\mathrm{st}}$ ), Cas9 binding scaffold, and transcriptional terminator. (B) Scheme of the plasmid self-curing. Introduction of plasmid pSC1 into strain BS-C100 and incubation in sporulation medium lead to the removal of pSC1; Ps and g1 indicate sporulation-specific promoter and gRNA respectively. (C) After self-curing, all B. subtilis colonies were grown on LB neomycin (LB neo) plates, but did not grow on LB chloramphenicol (LB cm) plates.

promoter (So et al., 2017) and the donor DNA, while the pG2aE has the donor DNA and two sgRNAs-the aprE- and selftargeting sgRNAs. After introducing the two plasmids into the BS-C100, transformants were used to measure the efficiency of the aprE gene deletion and sgRNA-containing plasmid curing. Both plasmids showed similar aprE deletion efficiencies (80\%), but different plasmid curing efficiencies. The curing efficiency of the plasmid pG-aE, which carries no $\operatorname{sgRNA}_{\text {st }}$, was less than $20 \%$, while the efficiency of the plasmid pG2-aE, which contains both $\operatorname{sgRNA}_{\mathrm{ct}}$ and sgRNA $\mathrm{Rt}_{\mathrm{st}}$, showed $74 \%$. The curing efficiency of pG2-aE was reduced compared to the plasmid pSC1 containing only sgRNA $\mathrm{st}_{\text {st }}$, which exhibited $100 \%$ efficiency. However, the efficiency was restored to $98 \%$ when the cas 9 expression was induced by the IPTG (Figure 3B). The results showed that our system can induce both genomic target-editing and removal of sgRNA-containing plasmids, in a growth-phase dependent manner, and the curing efficiency can be increased by the overexpression of the cas 9 gene.

\section{Consecutive Deletion of Eight Extracellular Protease Genes}

$B$. subtilis has eight extracellular proteases known as: aprE, $n p r E$, epr, $b p r, m p r, n p r B, v p r$, and $w p r A$. Extracellular protease deficient $B$. subtilis strains, such as WB800, were constructed to enhance the stability of the secreted heterologous proteins (Westers et al., 2006; Phuong et al., 2012). The WB800 strain carries antibiotic resistance markers that confer resistances to bleomycin, blasticidin S, hygromycin, and chloramphenicol (Wu et al., 2002). The chloramphenicol resistance gene was disrupted due to the insertion of neomycin resistance genes in the B. subtilis WB800N strain (Jeong H. et al., 2018). The construction of an eight, extracellular protease deficient mutant can be a good example for demonstrating our system. Eight plasmids (from
pG2-aE to pG2-wA) were constructed to perform the consecutive deleting of the eight protease genes (Table 1). We sequentially introduced the eight plasmids into the BS-C100. Through the repetitive process of genome editing and plasmid self-curing, eight strains from BS-D119 to BS-D126 were obtained. Eight protease deficiencies of the final strain BS-D126 were confirmed by the PCR, using eight primer sets $\mathrm{x}-\mathrm{NF} 1 / \mathrm{x}-\mathrm{CR} 1$ and DNA sequencing (Figures $4 \mathbf{A}, \mathbf{B}$ ). The efficiencies of gene deletion and plasmid curing of each mutant strain did not change significantly (Figure 4C). The protease assay showed that its extracellular activity was cumulatively decreased by the sequential removal of eight extracellular protease genes (Figure 5).

\section{DISCUSSION}

The genome editing of $B$. subtilis has been achieved by using antibiotic resistance markers for positive selection. However, $B$ subtilis is a generally recognized as safe (GRAS) microorganism and has been used on many industrial applications requiring to be free of antibiotic resistance markers. Thus, the food-grade genome editing methods are needed for B. subtilis. Various counter-selectable markers such as upp (Fabret et al., 2002), blaI (Brans et al., 2004), mazF (Zhang et al., 2006), araR (Liu et al., 2008), and hewI (Wang et al., 2012) have been used to replace the antibiotic resistance markers in the genome editing of B. subtilis. However, the methods using upp, blaI, and $\operatorname{araR}$ require prior modifications on the second region of the chromosome and left traces of foreign DNA in the genome. The methods using toxic genes, such as mazF and hewI often generate undesired spontaneous resistant mutants. To overcome the limitation of the previous methods, a genome editing method using a synthetic gene circuit was developed (Jeong et al., 2015). 


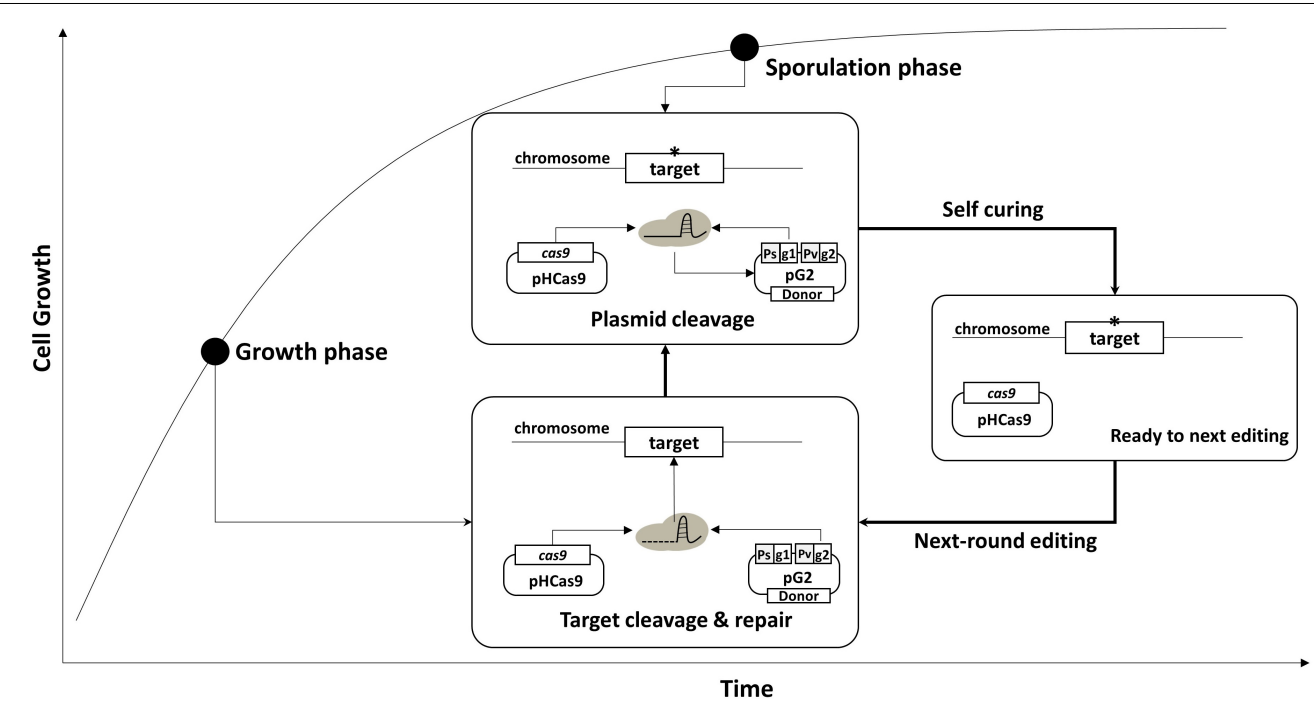

FIGURE 2 | Strategy for serial genome editing in B. subtilis. The pG2 plasmid containing sgRNA $A_{c t}$, sgRNA $A_{s t}$, and donor DNA fragment is introduced into pHCas9-containing cells. In the growth phase, sgRNA $A_{c t} /$ Cas9 complex is responsible for target gene editing. In the sporulation phase, sgRNA $/$ Cas9 complex make double strand breaks in the replication origin (rep) of the pG2 for self-curing. Thus, the cells are ready for the next round of editing which can be transformed with the new pG2 plasmid.

Since CRISPR/Cas9-mediated genome editing methods have been widely spread, they have also been applied in B. subtilis, recently (Hong et al., 2018).

CRISPR/Cas9-mediated genome editing in B. subtilis has been carried out through chromosomal expression (Westbrook et al., 2016) or plasmid-based methods (Altenbuchner, 2016; Zhang et al., 2016; So et al., 2017). The chromosomal expression method enabled site-specific mutation, gene insertion, continuous genome editing, multiplexing and CRISPR interference (Westbrook et al., 2016). However, consecutive genome editing using the chromosomal integration system requires repeated restoration of the native $t h r C$ locus, which is the gRNA integration site. Furthermore, using toxic genes, such as mazF to restore the native thrC gene locus may result in undesirable spontaneous resistance mutations. An all-in-one system in which the cas9, gRNA, and donor DNA are assembled in a single plasmid was successfully used to delete the 25.1 and $4.1 \mathrm{~kb}$ DNA fragments from the genome and repair the $\operatorname{trp} C 2$ mutation of B. subtilis 168 (Altenbuchner, 2016). Another all-in-one system was used to multigene disruption in undomesticated $B$. subtilis ATCC 6051a (Zhang et al., 2016). Although the single plasmid systems have been successfully used on the genome editing of B. subtilis, the large-sized plasmid may limit restriction enzyme sites for cloning and affect negatively to transformation and mutation efficiencies. We have also tried to use the all-in-one system. However, we obtained very poor mutation efficiency under our experimental condition. Thus, we modified the twoplasmid system previously reported for multi-round genome editing in B. subtilis (So et al., 2017).

All the plasmid-based approaches require the efficient replacement of the sgRNA-containing plasmid in multi gene editing. Plasmid curing has been commonly accomplished through serial subcultures in a non-selective medium and by

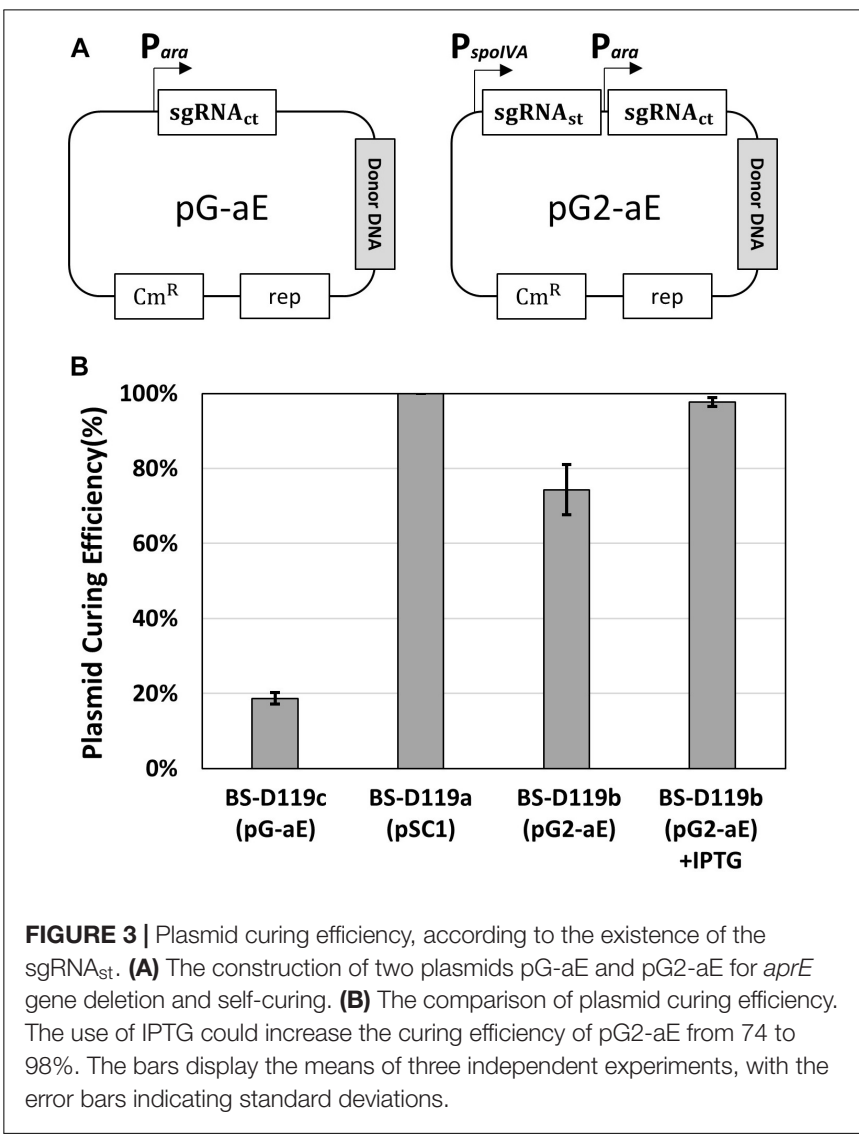

screening for the loss of plasmid. The temperature sensitive origin could be introduced for an efficient exclusion of vectors; however, those methods are laborious and time-consuming. 


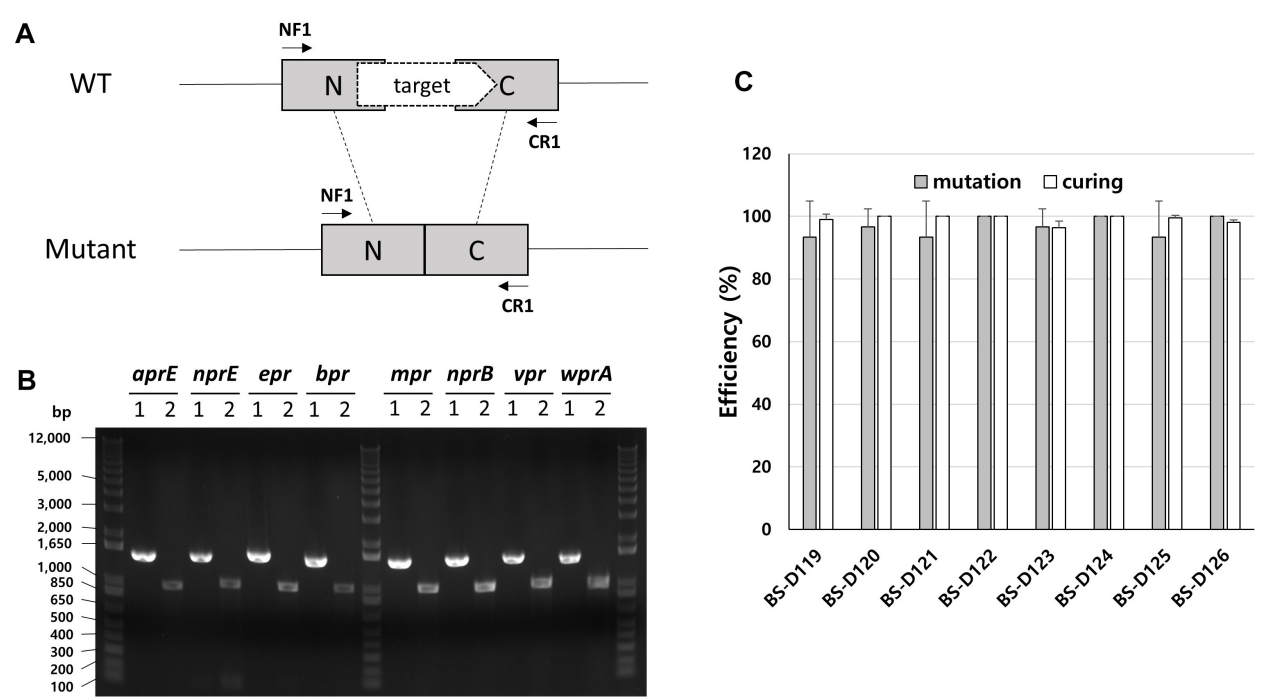

FIGURE 4 | Deletion of eight extracellular protease genes in B. subtilis. (A) The chromosome structure of wild type strain (B. subtilis 168) and the deletion mutants of protease genes. The squared $\mathrm{N}$ and $\mathrm{C}$ indicate 500 bp donor DNA of each $\mathrm{N}$ - and C-terminus. The arrows indicate primer binding regions. (B) PCR analysis for confirming the deletion of each extracellular protease gene, using primer sets NF1/CR1. 1 indicates a wild type strain and 2 indicates strain BS-D126. Expected sizes of PCR products are 1.5 and $1.0 \mathrm{~kb}$ from wild type and mutant, respectively. (C) The mutation (gray) and curing (white) efficiencies of each mutant strain. The bars display the means of three independent experiments, with the error bars indicating standard deviations.

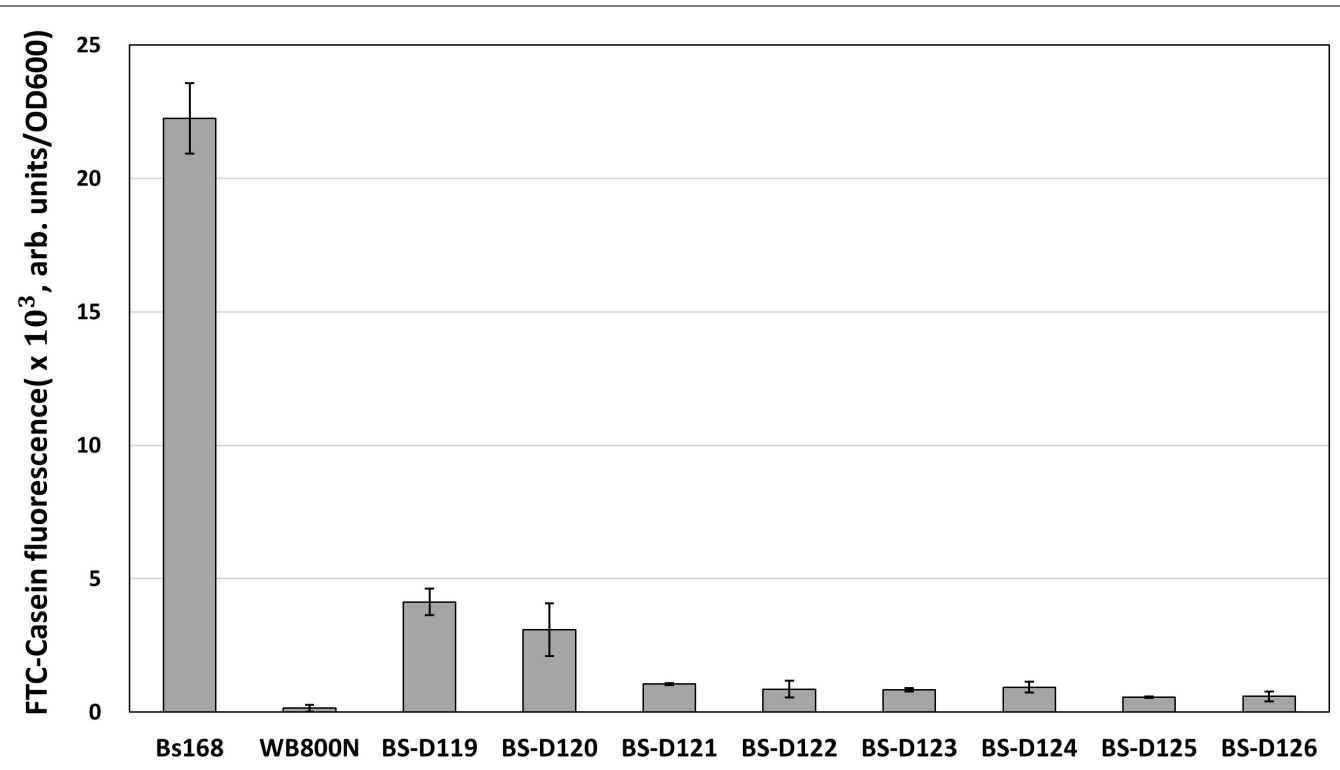

FIGURE 5 | The protease assay using FTC-Casein as substrate for confirming the serial deletion of extracellular protease genes. The protease activity of deletion mutants is compared to the wild type strain (B. subtilis 168) and the WB800N. The protease activity was assessed as changes in fluorescence through the digestion of the FTC-Casein substrate. The bars display the means of three independent experiments, with the error bars indicating standard deviations.

Otherwise, counter selection markers may be included in the plasmid backbone, but these tend to cause mutational escape and often require particular conditions for the medium and host (Reyrat et al., 1998). In this study, we introduced the sgRNA to remove the sgRNA-containing plasmid. To avoid the sgRNAcontaining plasmid removal, prior genome editing, the sgRNA $\mathrm{At}_{\mathrm{c}}$

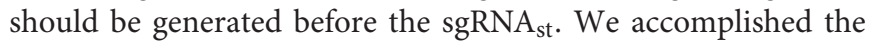
condition by using the spoIVA promoter, which is completely repressed in the growth phase, to synthesize the sgRNA $\mathrm{A}_{\mathrm{st}}$, while the sgRNA $A_{c t}$ was synthesized under the control of the constitutive promoter. Thus, the temporal separation of the two sgRNA syntheses during cultivation enabled the genomic editing and sgRNA-containing plasmid removal to take place in sequence, which automatically made the cells ready for the next round in multiple genome editing. Our efficient gRNA removal system can largely simplify the multi-round genome editing process in 
comparison with the traditional negative selection methods for plasmid curing. Since the spoIVA promoter is a $\sigma^{E}$-dependent, our system is limited when the gene required for the activation of $\sigma^{E}$ is the deleting target, such as spooA and sigF. In that case, the stationary phase-specific promoter (Lee et al., 2010), the acetoin-regulated promoter (Silbersack et al., 2006) or phosphate starvation-inducible promoter (Qi et al., 1997; Choi and Saier, 2005) may be used for the synthesis of the sgRNA $\mathrm{st}_{\mathrm{st}}$ instead of the spoIVA promoter.

The curing efficiency using the plasmid containing both $\operatorname{sgRNA}_{c t}$ and $s g R N A_{\text {st }}$ was reduced to $74 \%$, while the plasmid including only one $\operatorname{sgRNA}_{\text {st }}$ showed $100 \%$ curing efficiency (Figure 3). We found that the curing efficiency using the plasmid containing both $\operatorname{sgRNA}$ ct and $s g R N A_{\text {st }}$ was restored to $98 \%$ when the expression of the cas 9 gene was induced by the IPTG. Thus, the reduction of the curing efficiency when using two sgRNAs may be due to insufficient amounts of Cas9 protein to produce sufficient $\operatorname{sgRNA}_{\mathrm{st}} / \mathrm{Cas} 9$ complex at the sporulation phase, than when one sgRNA $A_{\text {st }}$ is used. A previous report showed that the leaky expression of the Cas9 without IPTG induction was enough to make an efficient mutation of the B. subtilis genome (So et al., 2017), suggesting that IPTG induction does not significantly change the mutation efficiency. The replication origin of the gRNA-containing plasmid was derived from the plasmid pTA1060 with a copy number of about 5 in B. subtilis (Bron et al., 1987). Our results suggest that the amount of Cas9 expressed by IPTG induction is sufficient to eliminate the 5copy plasmid.

The self-curing system that we have developed here did not have the prerequisites, such as further gene sets and a host background. Although several inducible promoters have been reported for use in the Bacillus species (Bhavsar et al., 2001; Phan et al., 2006), they showed basal expression levels even without inducers. If the inducible promoters exhibiting

\section{REFERENCES}

Altenbuchner, J. (2016). Editing of the Bacillus subtilis genome by the CRISPRCas9 system. Appl. Environ. Microbiol. 82, 5421-5427. doi: 10.1128/AEM.01 453-16

Barrangou, R., and Marraffini, L. A. (2014). CRISPR-Cas systems: prokaryotes upgrade to adaptive immunity. Mol. Cell 54, 234-244. doi: 10.1016/j.molcel. 2014.03.011

Bassett, A. R., Tibbit, C., Ponting, C. P., and Liu, J.-L. (2013). Highly efficient targeted mutagenesis of Drosophila with the CRISPR/Cas9 system. Cell Rep. 4, 220-228. doi: 10.1016/j.celrep.2013.06.020

Bhavsar, A. P., Zhao, X., and Brown, E. D. (2001). Development and characterization of a xylose-dependent system for expression of cloned genes in Bacillus subtilis: conditional complementation of a teichoic acid mutant. Appl. Environ. Microbiol. 67, 403-410. doi: 10.1128/aem.67.1.403-410.2001

Brans, A., Filee, P., Chevigne, A., Claessens, A., and Joris, B. (2004). New integrative method to generate Bacillus subtilis recombinant strains free of selection markers. Appl. Environ. Microbiol. 70, 7241-7250. doi: 10.1128/aem.70.12. 7241-7250.2004

Bron, S., Bosma, P., Van Belkum, M., and Luxen, E. (1987). Stability function in the Bacillus subtilis plasmid pTA 1060. Plasmid 18, 8-15. doi: 10.1016/0147619x(87)90073-4

Burby, P. E., and Simmons, L. A. (2017). CRISPR/Cas9 editing of the Bacillus subtilis genome. Bio Protoc. 7:e2272. doi: 10.21769/BioProtoc.2272 leaky expressions are used, the sequential occurrence of genome editing, and plasmid self-curing may be difficult. The difficult tight-control of inducible promoters in the Bacillus species suggests that a sporulation-phase specific promoter is useful for the controlled expression of the sgRNA $A_{\text {st }}$ Although our system is proven through consecutive gene deletion, we believe that it is capable of performing all sorts of multiple genome editing, including point mutations and insertions. This system may be applied to other Bacillus strain engineering and would be helpful in academic research, industrial production, therapeutics, and agricultural applications. Also, other microorganisms other than Bacillus can easily perform multiple genome editing, if an appropriate stationary phase specific promoter is used for the sgRNA ${ }_{\text {st }}$ synthesis.

\section{AUTHOR CONTRIBUTIONS}

$\mathrm{S}-\mathrm{KC}$ designed the experiments. $\mathrm{HL}$ and $\mathrm{S}-\mathrm{KC}$ realized all experiments and wrote the manuscript. All authors reviewed the manuscript.

\section{FUNDING}

This study was supported by the KRIBB Research Initiative Program; and the Bio \& Medical Technology Development Program of the National Research Foundation (NRF) funded by the Korean Government (MSIT) (NRF-2018M3A9F3079565).

\section{ACKNOWLEDGMENTS}

We thank Joonhyuk Choi for technical assistance.

Choi, S. K., and Saier, M. H. (2005). Regulation of pho regulon gene expression by the carbon control protein A, CcpA, in Bacillus subtilis. J. Mol. Microbiol. Biotechnol. 10, 40-50. doi: 10.1159/000090347

Cobb, R. E., Wang, Y., and Zhao, H. (2014). High-efficiency multiplex genome editing of Streptomyces species using an engineered CRISPR/Cas system. ACS Synth. Biol. 4, 723-728. doi: 10.1021/sb500351f

DiCarlo, J. E., Norville, J. E., Mali, P., Rios, X., Aach, J., and Church, G. M. (2013). Genome engineering in Saccharomyces cerevisiae using CRISPR-Cas systems. Nucleic Acids Res. 41, 4336-4343. doi: 10.1093/nar/ gkt135

Doudna, J. A., and Charpentier, E. (2014). The new frontier of genome engineering with CRISPR-Cas9. Science 346:1258096. doi: 10.1126/science. 1258096

Fabret, C., Ehrlich, S. D., and Noirot, P. (2002). A new mutation delivery system for genome-scale approaches in Bacillus subtilis. Mol. Microbiol. 46, 25-36. doi: 10.1046/j.1365-2958.2002.03140.x

Harwood, C. R., and Cutting, S. M. (1990). Molecular Biological Methods for Bacillus. New York, NY: John Wiley \& Sons, Inc.

Hilbert, D. W., and Piggot, P. J. (2004). Compartmentalization of gene expression during Bacillus subtilis spore formation. Microbiol. Mol. Biol. Rev. 68, 234-262. doi: $10.1128 / \mathrm{mmbr} .68 .2 .234-262.2004$

Hong, K.-Q., Liu, D.-Y., Chen, T., and Wang, Z.-W. (2018). Recent advances in CRISPR/Cas9 mediated genome editing in Bacillus subtilis. World J. Microbiol. Biotechnol. 34:153. doi: 10.1007/s11274-018-2537-1 
Jeong, D. E., Park, S. H., Pan, J. G., Kim, E. J., and Choi, S. K. (2015). Genome engineering using a synthetic gene circuit in Bacillus subtilis. Nucleic Acids Res. 43:e42. doi: 10.1093/nar/gku1380

Jeong, D. E., So, Y., Park, S. Y., Park, S. H., and Choi, S. K. (2018). Random knock-in expression system for high yield production of heterologous protein in Bacillus subtilis. J. Biotechnol. 266, 50-58. doi: 10.1016/j.jbiotec.2017.12.007

Jeong, H., Jeong, D.-E., Park, S.-H., Kim, S. J., and Choi, S.-K. (2018). Complete genome sequence of Bacillus subtilis strain WB800N, an extracellular proteasedeficient derivative of strain 168. Microbiol. Resour. Announc. 7:e01380-18. doi: 10.1128/MRA.01380-18

Jiang, Y., Chen, B., Duan, C., Sun, B., Yang, J., and Yang, S. (2015). Multigene editing in the Escherichia coli genome using the CRISPR-Cas9 system. Appl. Environ. Microbiol. 8, 2506-2514. doi: 10.1128/AEM.04023-14

Jinek, M., Chylinski, K., Fonfara, I., Hauer, M., Doudna, J. A., and Charpentier, E. (2012). A programmable dual-RNA-guided DNA endonuclease in adaptive bacterial immunity. Science 337, 816-821. doi: 10.1126/science.1225829

Lauritsen, I., Porse, A., Sommer, M. O., and Nørholm, M. H. (2017). A versatile one-step CRISPR-Cas9 based approach to plasmid-curing. Microb. Cell Fact. 16:135. doi: 10.1186/s12934-017-0748-z

Lee, S. J., Pan, J. G., Park, S. H., and Choi, S. K. (2010). Development of a stationary phase-specific autoinducible expression system in Bacillus subtilis. J. Biotechnol. 149, 16-20. doi: 10.1016/j.jbiotec.2010.06.021

Li, Y., Lin, Z., Huang, C., Zhang, Y., Wang, Z., Tang, Y. J., et al. (2015). Metabolic engineering of Escherichia coli using CRISPR-Cas9 meditated genome editing. Metab. Eng. 31, 13-21. doi: 10.1016/j.ymben.2015.06.006

Liu, S., Endo, K., Ara, K., Ozaki, K., and Ogasawara, N. (2008). Introduction of marker-free deletions in Bacillus subtilis using the AraR repressor and the ara promoter. Microbiology 154, 2562-2570. doi: 10.1099/mic.0.2008/016881-0

Mali, P., Yang, L., Esvelt, K. M., Aach, J., Guell, M., Dicarlo, J. E., et al. (2013). RNA-guided human genome engineering via Cas9. Science 339, 823-826. doi: $10.1126 /$ science. 1232033

Phan, T. T., Nguyen, H. D., and Schumann, W. (2006). Novel plasmid-based expression vectors for intra- and extracellular production of recombinant proteins in Bacillus subtilis. Protein Expr. Purif. 46, 189-195. doi: 10.1016/j. pep.2005.07.005

Phuong, N. D., Jeong, Y. S., Selvaraj, T., Kim, S. K., Kim, Y. H., Jung, K. H., et al. (2012). Production of XynX, a large multimodular protein of Clostridium thermocellum, by protease-deficient Bacillus subtilis strains. Appl. Biochem. Biotechnol. 168, 375-382. doi: 10.1007/s12010-012-9781-x

Piggot, P. J., and Hilbert, D. W. (2004). Sporulation of Bacillus subtilis. Curr. Opin. Microbiol. 7, 579-586.

Qi, Y., Kobayashi, Y., and Hulett, F. M. (1997). The pst operon of Bacillus subtilis has a phosphate-regulated promoter and is involved in phosphate transport but not in regulation of the pho regulon. J. Bacteriol. 179, 2534-2539. doi: 10.1128/jb.179.8.2534-2539.1997

Reyrat, J.-M., Pelicic, V., Gicquel, B., and Rappuoli, R. (1998). Counterselectable markers: untapped tools for bacterial genetics and pathogenesis. Infect. Immun. 66, 4011-4017.

Roels, S., Driks, A., and Losick, R. (1992). Characterization of spoIVA, a sporulation gene involved in coat morphogenesis in Bacillus subtilis. J. Bacteriol. 174, 575-585. doi: 10.1128/jb.174.2.575-585.1992
Ronda, C., Pedersen, L. E., Sommer, M. O., and Nielsen, A. T. (2016). CRMAGE: CRISPR optimized MAGE recombineering. Sci. Rep. 6:19452. doi: 10.1038/ srep 19452

Shan, Q., Wang, Y., Li, J., Zhang, Y., Chen, K., Liang, Z., et al. (2013). Targeted genome modification of crop plants using a CRISPR-Cas system. Nat. Biotechnol. 31, 686-688. doi: 10.1038/nbt.2650

Shen, B., Zhang, J., Wu, H., Wang, J., Ma, K., Li, Z., et al. (2013). Generation of gene-modified mice via Cas9/RNA-mediated gene targeting. Cell Res. 23, 720-723. doi: 10.1038/cr.2013.46

Silbersack, J., Jurgen, B., Hecker, M., Schneidinger, B., Schmuck, R., and Schweder, T. (2006). An acetoin-regulated expression system of Bacillus subtilis. Appl. Microbiol. Biotechnol. 73, 895-903. doi: 10.1007/s00253-006-0549-5

So, Y., Park, S.-Y., Park, E.-H., Park, S.-H., Kim, E.-J., Pan, J.-G., et al. (2017). A highly efficient CRISPR-Cas9-mediated large genomic deletion in Bacillus subtilis. Front. Microbiol. 8:1167. doi: 10.3389/fmicb.2017.01167

Trevors, J. (1986). Plasmid curing in bacteria. FEMS Microbiol. Lett. 32, 149-157. doi: 10.1111/j.1574-6968.1986.tb01189.x

Wang, Y., Li, Z., Xu, J., Zeng, B., Ling, L., You, L., et al. (2013). The CRISPR/Cas system mediates efficient genome engineering in Bombyx mori. Cell Res. 23, 1414-1416. doi: 10.1038/cr.2013.146

Wang, Y., Weng, J., Waseem, R., Yin, X., Zhang, R., and Shen, Q. (2012). Bacillus subtilis genome editing using ssDNA with short homology regions. Nucleic Acids Res. 40:e91. doi: 10.1093/nar/gks248

Westbrook, A. W., Moo-Young, M., and Chou, C. P. (2016). Development of a CRISPR-Cas9 toolkit for comprehensive engineering of Bacillus subtilis. Appl. Environ. Microbiol. 82, 4876-4895. doi: 10.1128/AEM.01159-16

Westers, L., Dijkstra, D. S., Westers, H., Van Dijl, J. M., and Quax, W. J. (2006). Secretion of functional human interleukin-3 from Bacillus subtilis. J. Biotechnol. 123, 211-224. doi: 10.1016/j.jbiotec.2005.11.007

Wu, S. C., Yeung, J. C., Duan, Y., Ye, R., Szarka, S. J., Habibi, H. R., et al. (2002). Functional production and characterization of a fibrin-specific singlechain antibody fragment from Bacillus subtilis: effects of molecular chaperones and a wall-bound protease on antibody fragment production. Appl. Environ. Microbiol. 68, 3261-3269. doi: 10.1128/aem.68.7.3261-3269.2002

Zhang, K., Duan, X., and Wu, J. (2016). Multigene disruption in undomesticated Bacillus subtilis ATCC 6051a using the CRISPR/Cas9 system. Sci. Rep. 6:27943. doi: 10.1038/srep27943

Zhang, X. Z., Yan, X., Cui, Z. L., Hong, Q., and Li, S. P. (2006). mazF, a novel counter-selectable marker for unmarked chromosomal manipulation in Bacillus subtilis. Nucleic Acids Res. 34:e71. doi: 10.1093/nar/gkl358

Conflict of Interest Statement: The authors declare that the research was conducted in the absence of any commercial or financial relationships that could be construed as a potential conflict of interest.

Copyright (C) 2019 Lim and Choi. This is an open-access article distributed under the terms of the Creative Commons Attribution License (CC BY). The use, distribution or reproduction in other forums is permitted, provided the original author(s) and the copyright owner(s) are credited and that the original publication in this journal is cited, in accordance with accepted academic practice. No use, distribution or reproduction is permitted which does not comply with these terms. 